\title{
A New Technique for Precise Microimplant Placement
}

\author{
${ }^{1}$ Divij Joshi, ${ }^{2}$ Vivek Patni, ${ }^{3}$ Girish Karandikar, ${ }^{4}$ VK Ravindranath
}

\section{ABSTRACT}

Aim: To explore a successful, much simpler, less cumbersome, and time-consuming technique for mini-implant placement.

Materials and methods: Crimpable hook, intraoral periapical radiograph, 15 number surgical blade.

Results: Very simple and efficient technique for mini-implant placement.

Conclusion: The proximity of roots in mandibular arch is major risk factor for placements of mini-implants. With the help of this technique, the proper direction and orientation of the miniimplant to be placed can be evaluated.

Clinical significance: There is no additional armamentarium required for this technique with the least clinical time for the operator providing a very efficient way for mini-implant placement.

Keywords: Anchorage, Mini-implant, Orthodontic treatment, Temporary anchorage device.

How to cite this article: Joshi D, Patni V, Karandikar G, Ravindranath VK. A New Technique for Precise Microimplant Placement. J Contemp Dent 2016;6(3):157-160.

\section{Source of support: Nil}

Conflict of interest: None

\section{INTRODUCTION}

The growing demand for minimum compliance and maximum curative has made the temporary anchorage device (TAD) more promising as an excellent alternative effects to traditional orthodontic anchorage. ${ }^{1-5}$ Endosseous dental implants have served successfully as anchorage structures for orthodontic appliances, especially in patients whose dental elements lack quantity or quality. Traditional dental implants, such as the Branemark system, have many limitations that preclude common use as orthodontic anchorage. Implant size restricts the locations in which they can be placed. This limitation has evoked many implant designs and sizes., 3,-11

When using skeletal anchorage, such as osseous dental implants, miniplates, ${ }^{10}$ miniscrews, ${ }^{12,13}$ or microscrews, ${ }^{9,14-16}$ clinicians can expect reliable anchorage

\footnotetext{
${ }^{1}$ Lecturer, ${ }^{2}$ Reader, ${ }^{3}$ Professor, ${ }^{4}$ Professor and Head

${ }^{1-4}$ Department of Orthodontics, Mahatma Gandhi Mission's Dental College and Hospital, Navi Mumbai, Maharashtra, India

Corresponding Author: Divij Joshi, Lecturer, Department of Orthodontics, Mahatma Gandhi Mission's Dental College and Hospital, Navi Mumbai, Maharashtra, India, Phone: +912227437900, e-mail: drdivijjoshi@gmail.com
}

without patient compliance. One variety of TAD is substantially smaller than customary dental implants. These have been called mini-implants or microimplants. Orthodontists have been intrigued by the possibility of skeletal anchorage since the 1940s. In 1997, Kanomi ${ }^{9}$ first mentioned a temporarily placed miniscrew for orthodontic anchorage. Miniscrews have now become established orthodontic anchorage aids, with diameters of 1 to $2.3 \mathrm{~mm}$ and lengths of 4 to $21 \mathrm{~mm}$.

In recent years, microimplants have gained popularity in orthodontics. Microimplants are primarily placed in complex sites where critical anatomic structures, such as roots of teeth, may be damaged, so precise surgical planning is required prior to placement. Among all available anchorage devices, microscrew implants have increasingly been used for orthodontic anchorage because of their absolute anchorage, easy placement and removal, and low cost. The small size of microscrew implants allows them to be placed into bone between the teeth, thus expanding their clinical applications. With more patients treated with screw implants as anchorage, their stability is gathering attention. Hyo-Sang Park showed that the overall success rate of TAD was $91.6 \%$, on examining the clinical variables of screw-implant factors (type, diameter, and length), local host factors (occlusogingival positioning), and management factors (angle of placement, onset and method of force application) and concludes that to minimize the failure of screw implants, inflammation around the implant must be controlled. ${ }^{17}$

The ability to obtain absolute anchorage through bone-anchored devices has enabled orthodontists to eliminate the unwanted side effects associated with conventional approaches and to correct malocclusions that previously required complicated biomechanics or orthognathic surgery. The goal of this report was to introduce a newly developed and cost-effective technique for the placement of microimplants in interradicular areas and evaluate its accuracy.

\section{MATERIALS AND METHODS}

In the present innovative technique, devices used for precise placement of microimplant consist of simple and readily available armamentarium, such as adjustable crimpable hooks (long length), stainless steel millimeter ruler with indentations, mosquito forceps, bard parker handle with blade no. 15 , periosteal elevator, microimplant.

Ideally, the procedure for microimplant placement starts when patient is on rigid wire like $0.019 \times 0.025^{\prime \prime}$ stainless 
steel in $0.022^{\prime \prime}$ slot or $0.017 \times 0.025^{\prime \prime}$ stainless steel in $0.018^{\prime \prime}$ slot. The area of interest for microimplant placement is decided according to needs, like retraction, intrusion, etc.

The most common areas are: (1) Retromolar area, distobuccal to the lower second molar (LR and LD7), (2) buccal alveolar bone between the lower first and second molars (L67), (3) upper and lower anterior area (A), (4) buccal alveolar bone between the upper second premolar and the first molar, and between the upper first and second molars (U56 and U67), and (5) upper palatal alveolar bone between the first and second molars (UP). ${ }^{17}$

Length of adjustable crimpable hook (Fig. 1) was measured with the help of millimeter ruler and divider, which was $19 \mathrm{~mm}$ (Figs 2 and 3). Later, a long crimpable hooks was attached to $0.019 \times 0.025^{\prime \prime}$ stainless steel arch wire.

The area for microimplant placement is determined, and base with open facing of crimpable hook is attached to the main arch wire with mosquito forceps (Fig. 4).

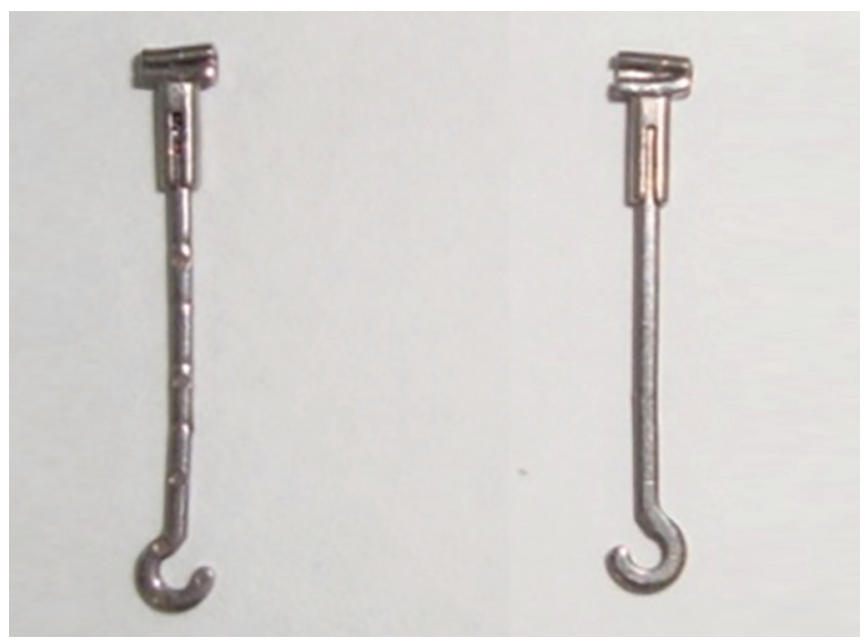

Fig. 1: Adjustable crimpable hook

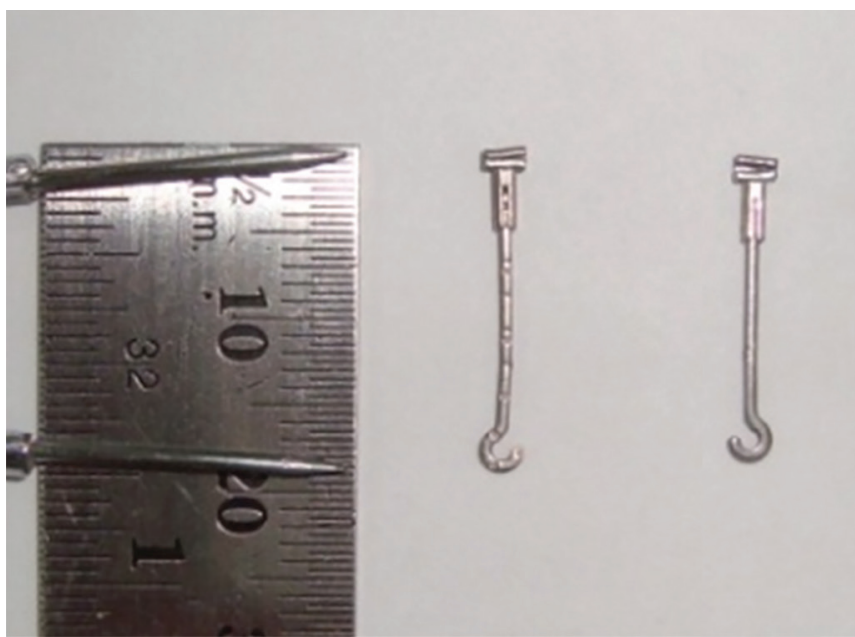

Fig. 3: Length of adjustable crimpable hook confirmed with the help of a divider (19 $\mathrm{mm}$ )
If needed root divergence is created before placing an implant to increase the interradicular distance. Because, when diameter of microimplant and the minimum clearance of alveolar bone are considered, interradicular space larger than $3 \mathrm{~mm}$ is needed for safe microimplant placement.

A periapical radiograph (paralleling cone technique) was taken to assess the location and level for implant placement. If necessary adjustment were made into the hook to ensure root contact (Fig. 5). Periapical radiograph was obtained and length of crimpable hook was measured from it. Magnification of radiograph was verified based on formula to get (exact level of implant clinically) clinical judgment of level of implant placement as follows:

$$
\mathrm{A} / \mathrm{B} \times 100=\ldots \text {. }
$$

where $A$ is the length of crimpable hook on intraoral radiograph; $\mathrm{B}$ is the original length of crimpable hook.

After determining the level, an incision is made with 15 number surgical blade and implant placement area is exposed (Fig. 6).

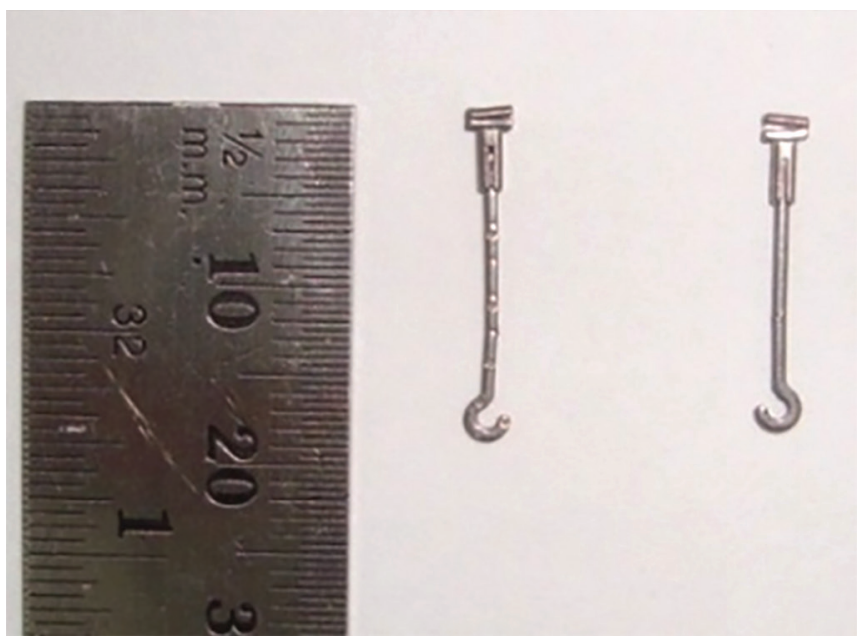

Fig. 2: Length of adjustable crimpable hook measured with the help of a millimeter ruler $(19 \mathrm{~mm})$

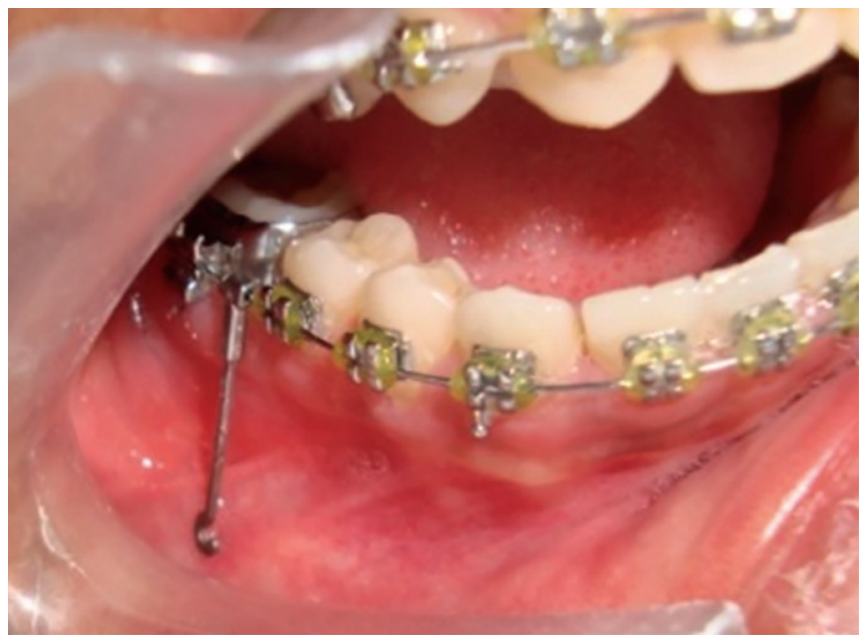

Fig. 4: The area for microimplant placement is determined with the crimpable hook attaching it to the main archwire 


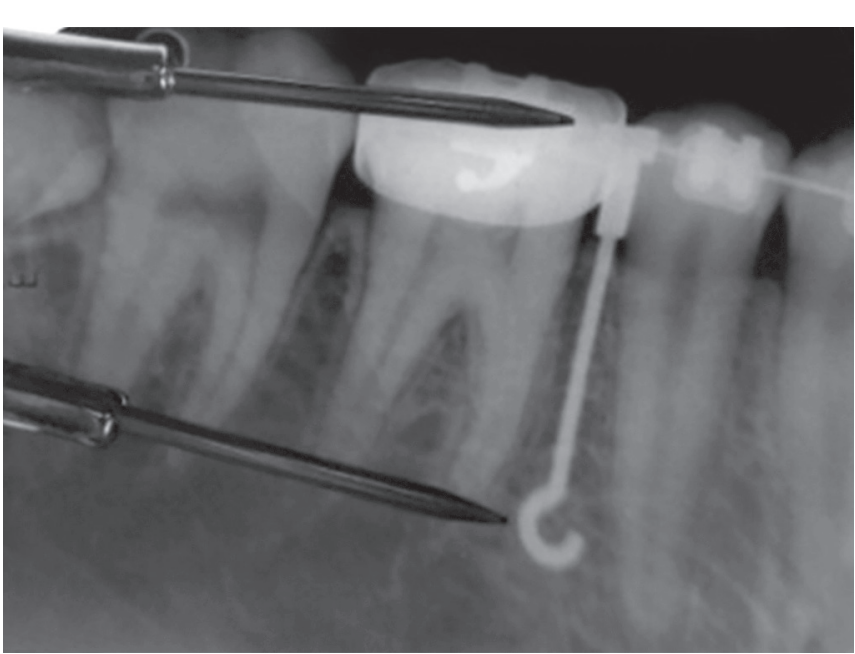

Fig. 5: A periapical radiograph was taken to assess the location and level for the mini-implant placement

\section{RESULTS}

The position for the placement and orientation of the mini-implant in the patient was successful. The miniimplant was later efficiently loaded on the same appointment as the placement and the needed orthodontic tooth movement was carried out effectively without any hindrance during the course of the orthodontic treatment.

\section{DISCUSSION}

The overall success rate was $91.6 \%$. The clinical variables of screw-implant factors (type, diameter, and length), local host factors (occlusogingival positioning), and management factors (angle of placement, onset and method of force application, ligature wire extension, exposure of screw head, and oral hygiene) did not show any statistical differences in success rates. General host factors (age, sex) had no statistical significance. Mobility, jaw (maxilla or mandible), and side of placement (right or left), and inflammation showed significant differences in success rates. Mobility, the right side of the jaw, and the mandible were the relative risk factors in the logistic regression analysis when excluding mobility, inflammation around the screw implants was added to the risk factors, affecting the clinical success of screw implants used as orthodontic anchorage. ${ }^{17}$

For a clinical evaluation of the data, it is important to combine the interradicular space measurements with the miniscrews' diameters and the bone clearance needed for both periodontal health and miniscrew stability. No data are available on how much bone is necessary between the miniscrews and the dental roots for both periodontal health and miniscrew stability. Considering that the width of periodontal ligament is approximately $0.25 \mathrm{~mm},{ }^{16}$ we assume that a minimum clearance of $1 \mathrm{~mm}$ of alveolar bone around the screw could be sufficient for periodontal health. ${ }^{5}$

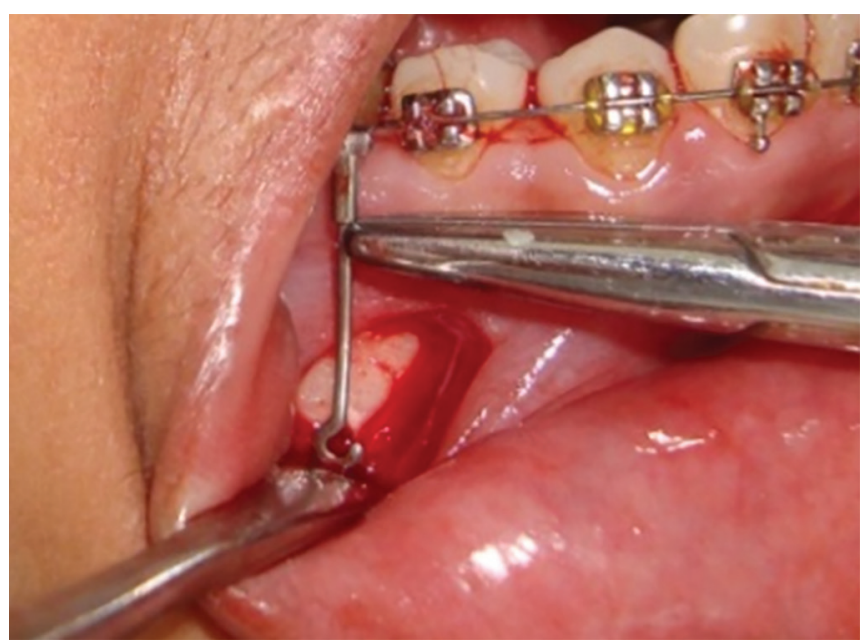

Fig. 6: After surgical exposure, the crimpable hook is used to guide the placement of the mini-implant

Root contact with a microimplant might increase the risk of failure. According to Kuroda et al, ${ }^{18}$ root proximity is a risk factor in microimplant failure. Therefore, it is necessary to prevent root contact when placing microimplants into alveolar bone. To minimize root contact, there are many approaches. Prealignment of teeth to create space and use of a brass wire guide and specially designed surgical guides were suggested. ${ }^{1}$

Microimplants placed close to the roots, as seen in radiographs, had a higher failure rate. Therefore, it is important to understand the shape and curvature of the roots. Surgical guides can be used to minimize root contacts. However, a contact point on a crown is usually used as the reference point to indicate the midpoint of the roots. Understanding the point of placement anteroposteriorly relative to the contact point and the angulation is important when placing microimplants. Because the interradicular space between the second premolars and first molars was widest in the maxilla, and the space between the first and second molars was widest in the mandible, these sites are the first choice for microimplant placement on the buccal side. ${ }^{19,20}$

Placement protocol strongly affected the stability of the implants. The screw implants were placed at 30 to $40^{\circ}$ angles to the long axes of the teeth in the maxillary arch and at 10 to $20^{\circ}$ angles in the mandibular posterior area. The screw implants in the retromolar area and the distobuccal bone to the mandibular second molars were placed at $90^{\circ}$ to the bone surface. The reason for placing the screw implants at those angulations was to reduce root contact by the screw implants without reducing the length of the screw. A long screw might have increased stability, and an angled screw provides more bone contact than a screw placed perpendicular to the bone. ${ }^{17}$

Microimplants placed in movable oral mucosa were more prone to inflammation than those in attached 
gingiva, and it was also a risk factor for failure. However, to place a microimplant in attached gingiva, it needs to be near the cervical area where there is less space between roots. By inclining the microimplant in an apical direction, its apex can be brought to the apical portion of roots where there is more space. As discussed previously, root contact can cause failure of microimplants. It seems safer to place microimplants not in attached gingival but in oral mucosa to minimize root contact. To reduce chances of root contact, it is better to place microimplants in the apical area and incline them apically. ${ }^{21,22}$

However, even with all these methods, a thorough understanding of the anatomic relationships between roots and surrounding structures is essential. Clinicians normally take periapical or panoramic radiographs to check the roots. With two-dimensional (2D) images, accurate information cannot be obtained because of magnification and distortion, especially with overlapped images.

Dental cone beam computed tomography (CT) has low radiation exposure compared with conventional medical CT and might be a useful tool for assessing root contact. Three-dimensional (3D) CT images can provide a better understanding of the relationships between roots. However, clinicians might not take 3D CT images of all patients. The relationships of anatomic structures surrounding the teeth must be understood for choosing the most suitable sites and the safest method to minimize root contacts. ${ }^{17}$

\section{CONCLUSION}

The proximity of miniscrews to the adjacent tooth root is a major risk factor for failure of screw anchorage. This tendency is more obvious in the mandible, suggesting that screw placement to avoid root proximity is important for the stability of miniscrews for orthodontic anchorage, which with the help of this technique the proper direction and orientation of the mini-implant to be placed can be evaluated.

\section{CLINICAL SIGNIFICANCE}

The mentioned technique of mini-implant placement involves no additional armamentarium besides the ready available "crimpable hooks" present in most of the orthodontic practices. In addition, this new method does not involve any cumbersome method or technique for mini-implant placement; on the contrary it requires only a routine X-ray to be advised saving the clinician's time and expenditure significantly.

\section{REFERENCES}

1. Bae SM, Park HS, Kyung HM, Kwon OW, Sung JH. Clinical application of micro-implant. J Clin Orthod 2002 May;36(5):298-302.
2. Deguchi T, Yamamoto TT, Kanomi R, Hartsfield JK Jr, Roberts WE, Garetto LP. The use of small titanium screws for orthodontic anchorage. J Dent Res 2003 May;82(5):377-381.

3. Miano BG, Bednar J, Pagin P, Mura P. The spider screw for skeletal anchorage. J Clin Orthod 2003 Feb;37(2):90-97.

4. Carano A, Velo S, Incorvati C, Poggio P. Clinical applications of the mini-screw-anchorage-system (MAS) in the maxillary alveolar bone. Prog Orthod 2004;5(2):212-235.

5. Poggio PM, Incorvati C, Velo S, Carano A. "Safe zones": a guide for miniscrew positioning in the maxillary and mandibular arch. Angle Orthod 2006 Mar;76(2):191-197.

6. Block MS, Hoffman DR. A new device for absolute anchorage for orthodontics. Am J Orthod Dentofacial Orthop 1995 Mar;107(3):251-258.

7. Favero L, Brollo P, Bressann E. Orthodontic anchorage with specific fixtures: related study analysis. Am J Orthod Dentofacial Orthop 2002 Jul;122(1):84-94.

8. Glatzmaier J, Wehrbein H, Diedrich P. Biodegradable implants for orthodontic anchorage. A preliminary biomechanical study. Eur J Orthod 1996 Oct;18(5):465-469.

9. Kanomi R. Mini-implant for orthodontic anchorage. J Clin Orthod 1997 Nov;31(11):763-767.

10. Umemori M, Sugawara J, Mitani $H$, Nagasaka H,Kawamura $H$. Skeletal anchorage system for open-bite correction. Am J Orthod Dentofacial Orthop 1999 Feb;115(2):166-174.

11. Wehrbein H, Feifel N, Diedrich P. Palatal implant anchorage reinforcement of posterior teeth: a prospective study. Am J Orthod Dentofacial Orthop 1999 Dec;116(6):678-686.

12. Creekmore TD, Eklund MK. The possibility of skeletal anchorage. J Clin Orthod 1983 Apr;17(4):266-269.

13. Costa A, Raffaini M, Melsen B. Miniscrews as orthodontic anchorage: a preliminary report. Int J Adult Orthod Orthognath Surg 1998;13(3):201-209.

14. Park HS. The skeletal cortical anchorage using titanium microscrew implants. Korean J Orthod 1999;29:699-706.

15. Park HS. The use of micro-implant as orthodontic anchorage. Seoul, Korea: Narae; 2001.

16. Park HS, Kwon TG, Sung JH. Nonextraction treatment with microscrew implants. Angle Orthod 2004 Aug;74(4):539-549.

17. Park HS, Jeong SH, Kwonc OW. Factors affecting the clinical success of screw implants used as orthodontic anchorage. Am J Orthod Dentofacial Orthop 2006 Jul;130(1):18-25.

18. Kuroda S, Yamada K, Deguchi T, Hashimoto T, Kyung HM, Yamamoto TT. Root proximity is a major factor for screw failure in orthodontic anchorage. Am J Orthod Dentofacial Orthop 2007 Apr;131(Suppl 4):S68-S73.

19. Han SH. The qualitative and quantitative analysis of maxilla and mandible using CT images in adolescent patients [thesis]. Daegu, Korea: Kyungpook University; 2006.

20. Park HS. An anatomical study using CT image for the implantation of micro implants. Korean J Orthod 2002;32: 435-441.

21. Miyawaki S, Koyama I, Inoue M, Mishima K, Sugahara T, Takano-Yamamoto T. Factors associated with the stability of titanium screws placed in the posterior region for orthodontic anchorage. Am J Orthod Dentofacial Orthop 2003 Oct;124(4):373-378.

22. Cheng SJ, Tseng IY, Lee JJ, Kok SH. A prospective study of the risk factors associated with failure of mini-implants used for orthodontic anchorage. Int J Oral Maxillofac Implants 2004 Jan-Feb;19(1):100-106. 